\title{
Finger-jointing of green Eucalyptus globulus L. wood with one-component polyurethane adhesives
}

\author{
Oscar González-Prieto ${ }^{1}$ (D) . José Manuel Casas Mirás ${ }^{2} \cdot$ Luis Ortiz Torres $^{1}$
}

Received: 7 February 2021 / Accepted: 2 November 2021 / Published online: 23 November 2021

(c) The Author(s) 2021

\begin{abstract}
The use of glued finger joint in green wood, directly from the sawing process, would open the possibility to obtain glued timber from small-sized wood, achieving an efficient use of the original raw material. The gluing of finger-jointed green wood, with moisture content above the fibre saturation point, may improve the efficiency and the manufacturing process of glulam or joinery. This may be especially beneficial for a hardwood such as Eucalyptus globulus L., which is a globally important forest resource, but is a challenging wood to dry. This article presents a study on the possibility to develop finger joints with wood in green state. To compare them, conventional finger joints on dry wood and solid boards without end joints were also manufactured. Cold-setting and fast-curing commercial one-component polyurethane adhesive systems were used. Finger-jointed samples were tested to determine mean and characteristic values (5th percentile) of density, bending strength and modulus of elasticity, and the results were analysed and discussed. Green-glued joints showed no statistically significant differences compared to the solid boards and improved strength properties with respect to dry-glued joints.
\end{abstract}

\section{Introduction}

Blue gum, Eucalyptus globulus, is an important plantation tree species worldwide, especially in Mediterranean climates of Europe, in South America and in its native region of Australia (Kirkpatrick, 1975). Its rapid growth, light wood and high mechanical properties make it suitable for various purposes. However, in the Iberian Peninsula, it is mainly used for pulp in the paper industry, as well as for the construction of floors and roofs, albeit in smaller quantities. Its use in other areas, such as structural timber, would only be possible if the gluing and drying processes were efficient. The possibility of gluing the finger joints before the drying process reduces the raw material losses and improves the final quality of the product after drying.

Gluing is the common process to increase wood lengthwise, using mainly finger joint to splice boards head to head.

Oscar González-Prieto

oscargprieto@uvigo.es

1 Department of Natural Resources and Environment Engineering, Escuela de Ingeniería Forestales Pontevedra, University of Vigo, 36006 Pontevedra, Spain

2 Department Applied Mathematics I, ETS Ingeniería de Telecomunicaciones Campus Central Vigo, University of Vigo, 36310 Pontevedra, Spain
The moisture content (MC) upon jointing interacts strongly with the adhesive. Conventional gluing of finger joints for softwood and hardwood is carried out on dry wood, preferably with a MC of 12-18\%; however, Blümer (2005) and Sterley et al. (2004) described some advantages of green finger jointing in technical, economic and environmental aspects. Some of these advantages are identified as: (1) less raw material, finding $16 \%$ less material for green fingerjointed grade C24 structural spruce timber, compared to the dry finger-jointed timber of the same grade as a reference; (2) increases in the quality of the final drying process, like less distortions and shrinkages; (3) increased revenue for by-products, such as pulp chips compared to dry chips; (4) shorter lead time from order to shipping; (5) no energy needed for preheating cross-cut wood surfaces; (6) the possibility of using cold adhesives and cold pressing to connect joints; (7) the high MC in the fibre, which allows for a greater initial contact between the surfaces to bond, due to the high ductility; (8) cost reduction, on the one hand, for kiln drying, which reduces the energy requirements, as only the best parts of the wood are selected and dried after gluing, thus less undesired parts need to be dried (e.g., defects or knots), and, on the other hand, less pressure is needed to glue green wood; and (9) the decrease in the use of formaldehyde-free adhesives. 
The growing demand for timber, leading to younger trees, with fast growing and thin logs, and a great proportion of juvenile wood, has an unavoidable need for gluing to achieve final products with larger sizes, although this raw material shows more drying difficulties. Gluing of green timber was first used over 20 years ago with the finger-jointing technique (Parker 1994; Stephens 1995) and has been successfully tested by many researchers with several adhesive types and processes (Karastergiou et al. 2008; Srivaro et al. 2019; Wessels et al. 2020).

In the use of green gluing with finger-jointing for structural timber products, there are several important conditioning parameters, such as the previous classification of wood in green state, the density of the wood in dry state and the dry process once the wood is glued to reduce the MC, as well as the adequate performance of the adhesives and the process. In this sense, Troughton and Chow $(1979,1980)$ successfully developed and tested finger joints from unseasoned rough western red cedar and spruce, with 30-100\% $\mathrm{MC}$, using commercial phenol-resorcinol glues. Good results were also shown by Parker (1994), with high-MC wood, using the Greenweld process with a specific formulation of phenol-resorcinol-formaldehyde (PRF) adhesive and an accelerator to manufacture engineered wood products. Karastergiou et al. (2008) and Sterley et al. (2004, 2014) reported very promising results on green-glued finger joints. Mantanis et al. (2011) investigated, with phenol resorcinol formaldehyde adhesive, the efficiency of green gluing with black pine, evaluating the bending strength and also the effect of finger joint orientation (vertical or horizontal fingers), obtaining a feasible modulus of rupture (MOR) and modulus of elasticity (MOE) of green glued finger-jointed specimens, and they also found that green finger joints prevented the boards from end-splitting and face gluing.

Research results on the bonding quality of green fingerjointed wood using 1C-PUR adhesive were generally very positive on several softwoods, as confirmed by Pommier and Elbez (2006) with maritime pine and Sterley et al. (2014) with spruce, and also with hardwoods, such as oak and eucalyptus. Karastergiou et al. (2008) studied the properties of finger jointing green Hungarian oak using 1C-PUR. The effect of finger-joint orientation (vertical or horizontal fingers) was also examined. In general, the results from the measurements of MOR and MOE of green-glued fingerjointed specimens indicated that the green gluing of a highdensity species such as oak wood is feasible. Crafford and Wessels (2016) used unseasoned Eucalyptus grandis with 1C-PUR adhesive and showed that the young finger-jointed lumber had very good bending, tensile parallel to grain and shear properties in green state. In this work, mean and characteristic MOR and MOE values of green finger-jointed wood were higher and the variation lower with respect to coniferous species, and the initial MC had a slight effect on both values. These results show the possibility of using this lumber in structural applications. Srivaro et al. (2019) suggest that the finger jointing process of green rubberwood with PUR and EPI adhesives could be performed without notably reducing the strength of the final products with respect to control dry finger joints. The previously cited authors have also reported good results for 1C-PUR with green or high-MC softwoods and hardwoods, showing that green-glued joints provide a wide, continuous wood/ adhesive interface from one substrate to the other, since the adhesive penetrates several cells deep and the density of the wood adjacent to the joint surfaces increases. Sterley et al. (2014) obtained results that also indicate that the adhesive forms covalent bonds with the wood substrate, in line with the findings of Di Landro et al. (1991) and Na et al. (2005). Wessels et al. (2020) found that green finger-jointing of $E$. grandis with 1C-PUR adhesive provided good quality bonds, although they also proposed new green stress grades before the gluing process.

Regarding the subsequent drying of green finger-jointed wood, Källander and Welling (2005) made a compilation focused on the drying of green glued wood and a study for dried green glued beams in a vacuum kiln. The results published on the drying of green glued material indicate that the drying procedure can be carried out with acceptable quality and similar to unglued or non-bonded wood if the $\mathrm{MC}$ variation and residual stresses are controlled within acceptable limits. Improvements were achieved compared to the drying of non-bonded wood regarding contractions and deformations, since the bonding prior to the drying of elements can be better for the balance of certain properties. For green glued material where two pieces are joined, such as finger joints, a combination of two pieces with different or unsuitable material properties can lead to severe twisting and bowing. Moreover, these authors proved that drying defects in green glued material normally lead to higher value losses compared to the corresponding drying degradation in non-bonded wood. The optimisation of the drying schedule must be focused on reducing damage rather than increasing the drying rate; however, since the lamellas that will be joined with a green finger joint are the size of the lamellae that would be used with dry wood, drying the lamellas with a green finger joint does not differ considerably from drying with non-bonded wood.

In relation to E. globulus, no relevant studies conducted with green finger joints were found. This wood is the second most important species in the Northern Iberian Peninsula (Spain and Portugal), where the largest extension of all Europe is found (Xunta de Galicia 2018). Despite its main uses as raw material to manufacture boards and pulp paper, using green glued finger jointing could lessen its main problem regarding the deformations and shrinkages as a consequence of the drying process. The main objective of this 
article was to investigate wet or green finger jointing in order to compare the mechanical behaviour of green and dry glued polyurethane joints, with the same 1C-PUR adhesive, and to compare it with solid wood without finger joints. The comparison of the characteristic values allowed determining whether the results are satisfactory with the grade classes for structural solid wood. This will show whether the use of an unconventional gluing system using green wood can add value and improve the efficiency of small log material from a species with high industrial potential.

\section{Materials and methods}

\subsection{Materials}

Finger joints were manufactured from wet and dry boards of clear wood of E. globulus. For comparison of the results, dried boards without finger joints were also tested. Each lamella was cut in the middle and rejoined again with a finger joint. Figure 1 shows the geometry and dimensions of the finger joint tested in this study.

All the lamellas were randomly selected from the common supply of the company Laminados Villapol S.A (Spain). The original trees came from the north of the Iberian Peninsula and had diameters greater than $30 \mathrm{~cm}$. The boards used did not contain sapwood, singularities or defects, such as knots, fiber deviation, pit and/or cracks. The cutting was in the radial direction. The visual classification under the criteria of the UNE 56546 (2013) standard was "MEF" class, with a characteristic bending strength of $47 \mathrm{~N} /$ $\mathrm{mm}^{2}$, characteristic modulus of elasticity of $13,500 \mathrm{~N} / \mathrm{mm}^{2}$ and with a mean density of $797 \mathrm{~kg} / \mathrm{m}^{3}$ (Fernández-Golfin et al. 2007). This classification is also included in the $\mathrm{D} 45$ class of EN 338 (2016).

\subsection{Gluing of finger joints}

Commercial cold setting 1C-PUR adhesive systems were employed, Jowapur ${ }^{\circledR} 686.60$ provided by Jowat AG-Germany. Glue in a spread rate of $210 \mathrm{~g} / \mathrm{m}^{2}$ was used to manufacture the green joints, applying it manually with a soaked brush and checking with a laboratory standard balance, putting over the lamella with one part of the finger joint and setting the null-value before the application of glue. The same process was repeated for each part, ensuring that all finger surfaces were covered. This allows excluding the variable "lack of wetting or diffusion". The machining of the teeth, their gluing, assembly and pressing were carried out in a short period of time. No primer surface treatment was applied, since similar previous works of Pommier and Elbez (2006), Sterley et al. (2014) and Karastergiou et al. (2008) did not include it. Fingers were visible on the flat side. For pressuring the finger joints, DIN 68,140-1(1999) norm was used as a reference, which establishes certain requirements for softwoods, like a pressure between 2 and $5 \mathrm{~N} / \mathrm{mm}^{2}$ for finger lengths $>35 \mathrm{~mm}$, and a pressure between 5 and $15 \mathrm{~N} /$ $\mathrm{mm}^{2}$ for shorter finger lengths $<35 \mathrm{~mm}$. It also establishes a maximum pressure for a minimum of $2 \mathrm{~s}$, achieving full contact between the surfaces. This was adapted to the green and dry E. globulus wood, utilizing an industrial press for pressing the green finger joints, with a nominal pressure in green joints of $7 \mathrm{~N} / \mathrm{mm}^{2}$ for $10 \mathrm{~s}$. This pressure was adjusted to minimise the risk of indentation due to excess compression

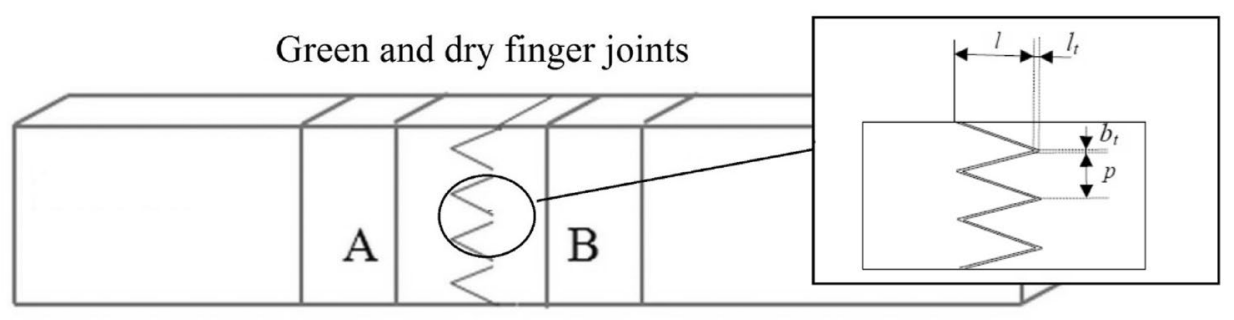

Solid wood without finger joint

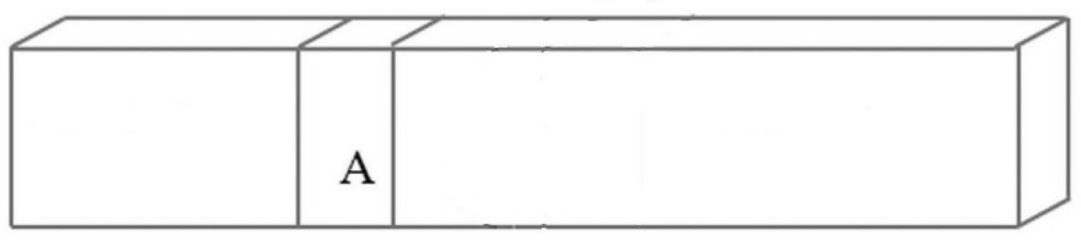

Fig. 1 Geometry and dimensions of the finger joint and solid wood specimens. $l=$ finger length $(9.5 \mathrm{~mm}), p=$ finger pitch $(4 \mathrm{~mm})$, $b_{t}=$ thickness of finger-tip $(1 \mathrm{~mm}), l_{t}=$ finger-tip gap $(1.5 \mathrm{~mm})$. Initial nominal dimension of lamellas: green finger joints lamellas
$102 \times 34 \times 760 \mathrm{~mm}$; dry finger joints lamellas $100 \times 24 \times 570 \mathrm{~mm}$ and solid wood lammellas $100 \times 24 \times 570 \mathrm{~mm}$. The final nominal dimensions of lamellas from green finger joints were $100 \mathrm{~mm}$ in width, $570 \mathrm{~mm}$ length and 29, 27, 23, and $20 \mathrm{~mm}$ thickness 
in the assembly of the teeth, since it works with much softer green wood. For dry glued joints the pressure was $12.5 \mathrm{~N} /$ $\mathrm{mm}^{2}$ for $10 \mathrm{~s}$. Once pressure had been applied, the specimens were carefully transferred to the curing area, where they remained for more than $4 \mathrm{~h}$.

\subsection{Bending tests}

Specimens with green-glued joints, specimens with dryglued joints and specimens without any type of joint were tested in the dry state. For this reason, all results correspond to a dry MC, with mean values between 10 and $12 \%$. The test was carried out to determine the mean and the characteristic value (corresponding to the 5 th percentile) of the bending strength, the global modulus of elasticity in bending and the density. For this work, the reference documents were the EN 14080 (2013), EN 15497 (2014) and EN 408 (2012) standards. Samples of finger joints with green and dried wood were determined as the mean value of two sections, cut as close as possible to the break zone and to each of the joined sheets (sections A and B in Fig. 1 top), once the green glued specimens were dry and tested, with a MC close to $12 \%$. For pieces of wood without a finger joint, density was obtained by measuring a section taken from a cut as close as possible to the break zone (section A in Fig. 1 bottom).

The initial nominal dimension of the green finger-jointed lamellas was $102 \times 34 \times 760 \mathrm{~mm}$, with a mean MC of $80 \%$. After gluing, they were dried in a conventional drying chamber. The same specific drying schedule based on the work of Baso et al. (2004) was used for all groups of specimens. With these drying conditions, the green finger-jointed lamellas with a thickness in green of $34 \mathrm{~mm}$ reached an average humidity of $10 \%$ in 122 days of drying. Once dried, the green finger-jointed lamellas were planed on both sides and edges. As the green glued finger-jointed lamellas had a different shrinkage grade in thickness by drying, four finally planed-thickness groups were established in order to develop the bending test, with a total of 127 finger joint samples. In general terms, in the planed thickness after green finger-joint gluing, a 75\% output was obtained (from $34 \mathrm{~mm}$ in green to 29-27-23-20 mm in dry state and planed), compared to the output after dry finger-joint gluing, which was $69 \%$ (34 mm in green to $24 \mathrm{~mm}$ planed). The causes of thickness reduction were not characterized or analysed in detail, since it was not an objective of this work, although a combination of collapse, deformations (cup) and shrinkages during the drying process may have affected the final thickness. Table 1 summaries the initial and the four final thickness groups before drying and planing, as well as the number of specimens in each group according to thickness.

In parallel, 50 dry finger joints were made with the same system in lamellas with dimensions of $100 \times 24 \times 570 \mathrm{~mm}$, with an initial MC of $11 \%$. A cut was made in the middle
Table 1 Final dimensions for testing the green glued toothed joint samples

\begin{tabular}{lll}
\hline $\begin{array}{l}\text { Initial nominal thick- } \\
\text { ness in green }\end{array}$ & $\begin{array}{l}\text { Final nominal thickness before } \\
\text { dry and brushed }(\mathrm{mm})\end{array}$ & $\begin{array}{l}\text { Number } \\
\text { of sam- } \\
\text { ples }\end{array}$ \\
\hline $34 \mathrm{~mm}$ & $29 \mathrm{~mm}$ & 10 \\
& $27 \mathrm{~mm}$ & 80 \\
$23 \mathrm{~mm}$ & 20 \\
& $20 \mathrm{~mm}$ & 15 \\
Total & & $\mathbf{1 2 7}$ \\
\hline
\end{tabular}

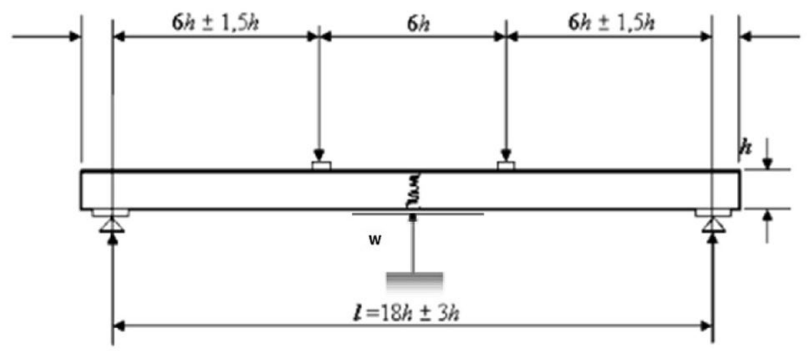

Fig. 2 Dimensions and position of the samples in the bending test where $h=$ depth of cross section in bending test $(\mathrm{mm})$. Original source: EN 408 (2012)

of each lamella, which was then re-joined with a finger joint. In addition, 30 dried specimens without joints were also tested, with dimensions of $100 \times 24 \times 570 \mathrm{~mm}$ and a MC of $12 \%$. All these lamellas were previously dried with the same process of green finger-joint lamellas. In total, 211 bending tests were carried out according to the criteria of the EN 408 standard (2012). The following properties were determined: $\mathrm{MC}$, density, mean and global modulus of elasticity in bending and bending strength.

Bending strength and global elasticity modulus were tested, laying the specimens according to the scheme in Fig. 2, where $h$ represents the depth of the cross section in the bending test $(\mathrm{mm})$. The calculation was made following Eq. 1 and 2;

$f m=\frac{3 F a}{b h^{2}}$

$E_{m, g}=\frac{3 a l^{2}-4 a^{3}}{2 b h^{3}\left(2 \frac{w_{2}-w_{1}}{F_{2}-F_{1}}-\frac{6 a}{5 G b h}\right)}$

where $f \mathrm{~m}$ is the bending strength $\left(\mathrm{N} / \mathrm{mm}^{2}\right), F$ is the maximum load $(\mathrm{N}), a$ is the distance between a loading position and the nearest support in a bending test $(\mathrm{mm})$, $b$ is the width of the cross section in bending test, or the smaller dimension of the cross section $(\mathrm{mm})$, and $h$ is the 


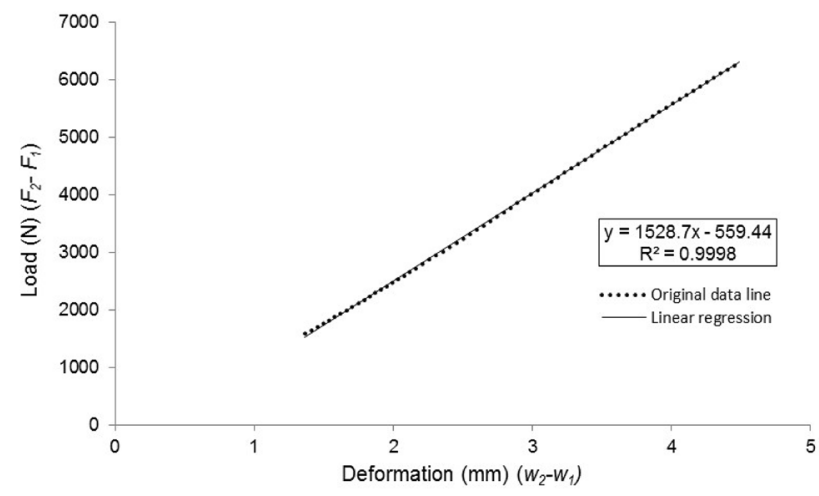

Fig. 3 Example of a green finger joint test of load-deformation graph within the range of elastic deformation with an adjust of $R^{2} \geq 0.99$

depth of the cross section in the bending test (mm). $F_{2}-F_{1}$ is an increment of load $(\mathrm{N})$ on the regression line with a correlation coefficient of 0.99 or higher, $w_{2}-w_{1}$ is the increment of deformation in mm corresponding to $F_{2}-F_{1}$ (Fig. 3) and $\mathrm{G}$ is the transversal elasticity modulus.

The data were statistically analysed using the Statgraphics C-XV software (v15.2.14) to perform a normality test (Shapiro-Wilk test), in order to determine the variance homoscedasticity (Levene's test) and to conduct an ANOVA test.

\section{Results and discussion}

The individual, mean and characteristic (5th percentile) values of bending strength $\left(\mathrm{N} / \mathrm{mm}^{2}\right)$, global modulus of elasticity $\left(\mathrm{N} / \mathrm{mm}^{2}\right)$ and density $\left(\mathrm{Kg} / \mathrm{m}^{3}\right)$ were determined and compared between the green glued finger joints, dry glued finger joints and the samples without finger joints. All these properties were determined with a MC close to
$12 \%$, as identified in Table 2. The different gluing pressure of the green and dry finger joints was not considered in this discussion, since this was adjusted to minimize the risk of indentation in the green finger assembly. The green finger joint is a much softer wood. Therefore, using the same pressure on the green and on the dry finger is not suitable. Thus, high pressure on dry wood would cause indentation with green wood, and low pressure on green wood would not be sufficient for dry wood.

\subsection{Density, glue, moisture content and destructive test results}

The green sample group had a mean MC of $80 \%$ at the time of gluing. After drying, the mean density of the 127 samples of green finger joint was $862 \mathrm{~kg} / \mathrm{m}^{3}$, with a standard deviation of $119 \mathrm{~kg} / \mathrm{m}^{3}$ (measured with $10 \% \mathrm{MC}$ ). There was a wide range of density values, from 589 to $1095 \mathrm{~kg} / \mathrm{m}^{3}$, with a standard deviation of $115 \mathrm{~kg} / \mathrm{m}^{3}$. Table 2 shows the mean density of the dry finger joints and for solid wood without finger joints. There were no great levels of variation in MC in green finger joints before gluing, with a standard deviation of $6.2 \%$.

The values for the green finger-joint density data shows a $p$ value of 0.071. Since the lowest $p$ value of the tests performed was $\geq 0.05$, the normal distribution cannot be rejected for green finger-joint density population with $95 \%$ interval (Fig. 4). Similar values were obtained for the density of dry finger joints and solid lamellas without using fingerjoint specimens, which had a normal distribution according to the same test. This population distribution on wood samples allowed approximating the value of a random variable to an ideal situation.

The results from the destructive values are summarized in Table 2. The majority of failures of the bending test
Table 2 Results of maximal load, MOE (global elasticity modulus), MOR (bending strength), density and MC (moisture content in bending test)

\begin{tabular}{llllllll}
\hline Finger joint group & & $\begin{array}{l}\text { Initial MC in } \\
\text { green state } \\
(\%)\end{array}$ & Max. Load (N) & $\begin{array}{l}\mathrm{MOE} \\
\left(\mathrm{N} / \mathrm{mm}^{2}\right)\end{array}$ & $\begin{array}{l}\text { MOR } \\
\left(\mathrm{N} / \mathrm{mm}^{2}\right)\end{array}$ & $\begin{array}{l}\text { Density } \\
\left(\mathrm{Kg} / \mathrm{m}^{3}\right)\end{array}$ & MC in test (\%) \\
\hline \multirow{2}{*}{ Green } & Mean & $80^{* *}$ & 14,503 & 20,288 & 107.7 & $862^{*}$ & 10 \\
& $\mathrm{SD}$ & 6.2 & 2487 & 3416 & 16.8 & 119.2 & 0.6 \\
& $\mathrm{CV}$ & 0.08 & 0.17 & 0.17 & 0.16 & 0.14 & 0.06 \\
\multirow{5}{*}{ Dry } & Mean & 11,779 & 18,856 & 83.8 & $776^{*}$ & $11^{* *}$ \\
& $\mathrm{SD}$ & 1548 & 2715 & 11.0 & 76.0 & 0.5 \\
\multirow{5}{*}{ Without finger } & $\mathrm{CV}$ & 0.13 & 0.14 & 0.13 & 0.10 & 0.05 \\
& $\mathrm{Mean}$ & 14,705 & 18,482 & 108,1 & 821 & $12^{* *}$ \\
& $\mathrm{SD}$ & 2044 & 2700 & 15.1 & 83.9 & 0.3 \\
& $\mathrm{CV}$ & 0.14 & 0.15 & 0.14 & 0.10 & 0.03 \\
\hline
\end{tabular}

$S D$ standard deviation, $C V$ coefficient of variation

*Determined as a mean of the density of each part joined at $12 \% \mathrm{MC}$

**Also corresponds to the initial MC of wood 
specimens occurred at or close to a finger joint in the board. A typical broken finger joint, in this case with a green finger joint, is shown in Fig. 5. This held true for both green and dry specimens in a similar way without detecting an obvious gluing failure.

In comparison with previous works with a high-density hardwood such as $Q$. conferta, Karastergiou et al. (2008) obtained mean MOR results of the green finger joint (vertical orientation and $10 \mathrm{~mm}$ finger length) with a reduction of $25 \%$ with respect to the solid wood without finger joints. However, in this work with E. globulus wood, there was no significant reduction between green finger joints (vertical orientation and $9.5 \mathrm{~mm}$ finger length) and the wood without finger joints. In relation to the mean MOE, previous work with $Q$. conferta had an increase of $12 \%$, while in this work E. globulus had an increase of $10 \%$ compared to solid wood without finger joints.

Crafford and Wessels (2016) found a good result for $E$. grandis, with a mean density of $425 \mathrm{~kg} / \mathrm{m}^{3}$, mean MOR of $43.7 \mathrm{~N} / \mathrm{mm}^{2}$ and mean MOE of $9826 \mathrm{~N} / \mathrm{mm}^{2}$ with green finger joints, tested in dry state. According to these data, and compared with the results of this work, since the wood of $E$. grandis had 50\% lower density than E. globulus, $60 \%$ lower MOR and 51\% lower MOE were obtained for E. grandis with respect to E. globulus. In absolute terms, the results were similar when taking into account the lower density of E. grandis.

\subsection{Comparison of the destructive test results}

The graphic comparison in the mean density values of the three groups of tests did not show significant differences (Fig. 6). As the three groups show a normal probability distribution, a Levene's test was used to assess the equality of variances. There was no statistically significant difference between the standard deviations of the three groups, with 95\% confidence level (Table 3). An ANOVA test was also

Green finger joint density normality test

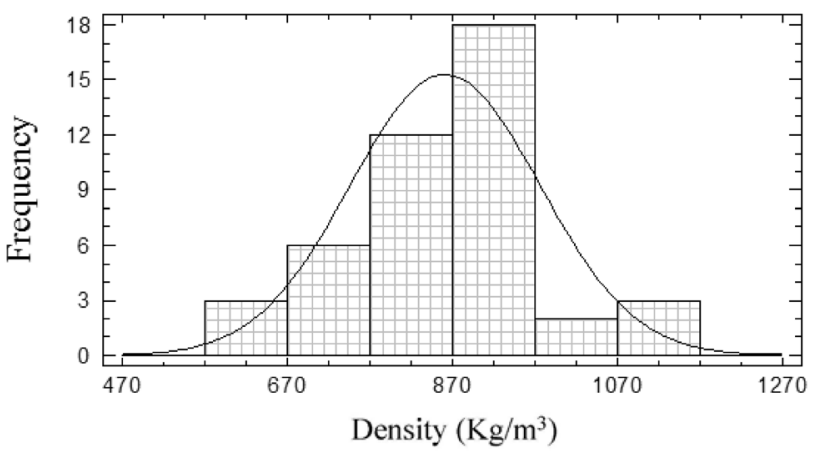

Fig. 4 Normality distribution for the green-glued finger joint population

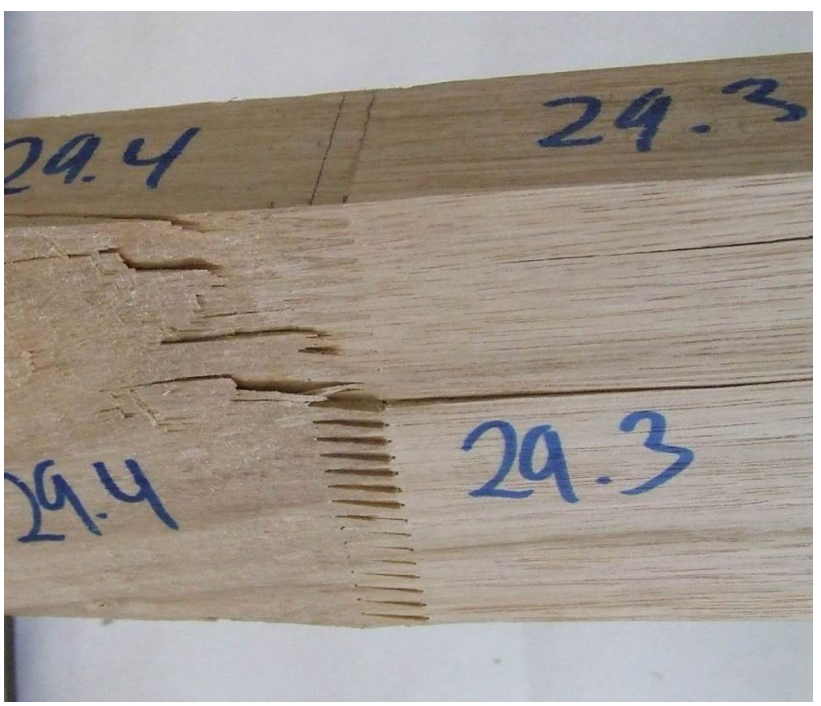

Fig. 5 Example of a green finger joint bending test showing a common failure near the finger joint (this lamella corresponds to the data of Fig. 3)

performed, which showed a statistically significant difference between the means of the 3 density groups, with $95 \%$ confidence level (Table 3).

Additionally, a Fisher's LSD test was carried out with the minimum significant difference procedure. No significant difference was found between wood without finger joints and with green and dry finger-joints (Table 4). A significant difference was found between the results of green and dry finger joints.

Moreover, the green finger joint did not remarkably decrease the MOR with respect to non-bonded wood (Fig. 7). The mean MOR value of green finger joints was $22 \%$ higher than the mean values of dry finger joints.

The ANOVA test of the three MOR groups showed statistically significant differences between the groups. Additionally, a Fisher's LSD test with the minimum significant difference procedure was carried out. Significant differences were found in the mean MOR between the green finger joints and dry finger joint, although no significant differences were detected between green finger joint and wood without finger joint.

In relation to the MOE results (Fig. 8), the ANOVA test of the three MOE groups showed statistically significant differences between the groups. Fisher's LSD test showed no significant differences in the mean MOE between the dry finger joints and the wood without finger joints. A significant increase in the mean value for the green finger joints was found, with respect to the dry finger joints and the wood without finger joints (7\% and $9 \%$ respectively).

According to the obtained results, the mechanical values were improved in the green-glued joints compared to the dry-glued joints. To interpret this information, it has to be 


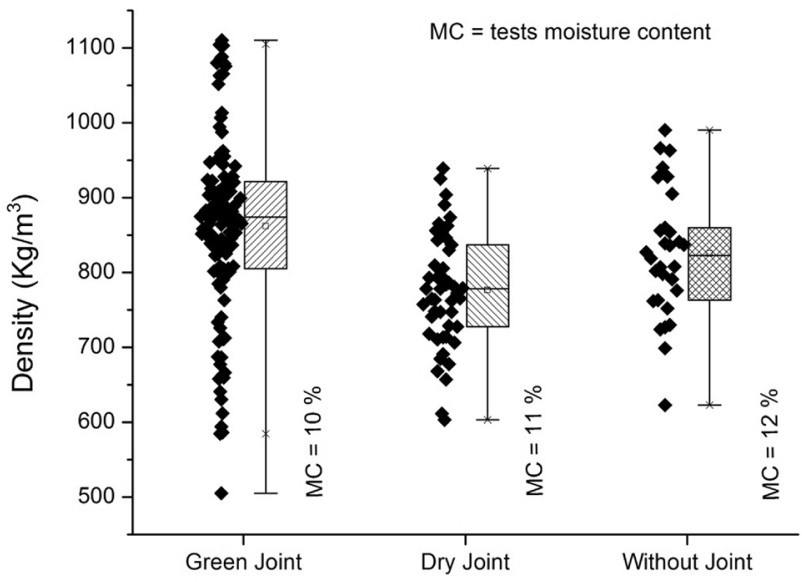

Fig. 6 Comparison of mean density values

Table 3 Results of the Levene's test and the ANOVA comparing density of green, dry, and without finger-joint groups

\begin{tabular}{|c|c|c|c|c|c|}
\hline \multirow{3}{*}{$\begin{array}{l}\text { Test of } \\
\text { Levene } \\
\text { ANOVA } \\
\text { Test }\end{array}$} & \multicolumn{4}{|l|}{ Test } & \multirow{3}{*}{$\begin{array}{l}P \text {-Value } \\
0.05903 \\
P \text {-Value }\end{array}$} \\
\hline & \multicolumn{4}{|l|}{2.86951} & \\
\hline & Square Sum & Gl & $\begin{array}{l}\text { Mean } \\
\text { square }\end{array}$ & $F$-Reason & \\
\hline $\begin{array}{r}\text { Between } \\
\text { groups }\end{array}$ & 267,305 & 2 & 133,652 & 11.96 & 0.000000 \\
\hline Intra groups & $2.26928 \mathrm{E} 6$ & 203 & $11,178.7$ & & \\
\hline Total (Corr.) & $2.53659 \mathrm{E} 6$ & 205 & & & \\
\hline
\end{tabular}

Table 4 Contrast method to discriminate between means is Fisher's least significant difference (LSD) procedure

\begin{tabular}{lrr}
\hline Contrast & Sig & Difference \\
\hline Density without finger-Density dry finger & & 45.0218 \\
Density without finger-Density green finger & & -40.7333 \\
Density dry finger-Density green finger & $*$ & -85.7551 \\
\hline
\end{tabular}

taken into consideration that the average density of the dry finger joint population was slightly lower and, therefore, its predictable mechanical properties would be lower. Moreover, the MC at the time when the tests were conducted was quite high, which could slightly increase the mechanical properties. In any case, the results show that gluing finger joints with wet wood was satisfactory.

Table 5 summarises for the three groups of samples the corresponding characteristic values (5th percentile values). Since the lamellas fulfill the requirements of the most demanding visual structural grade mentioned above, according to the structural codes, the 5th percentile values are relevant as 'characteristic' values used to design structures. In

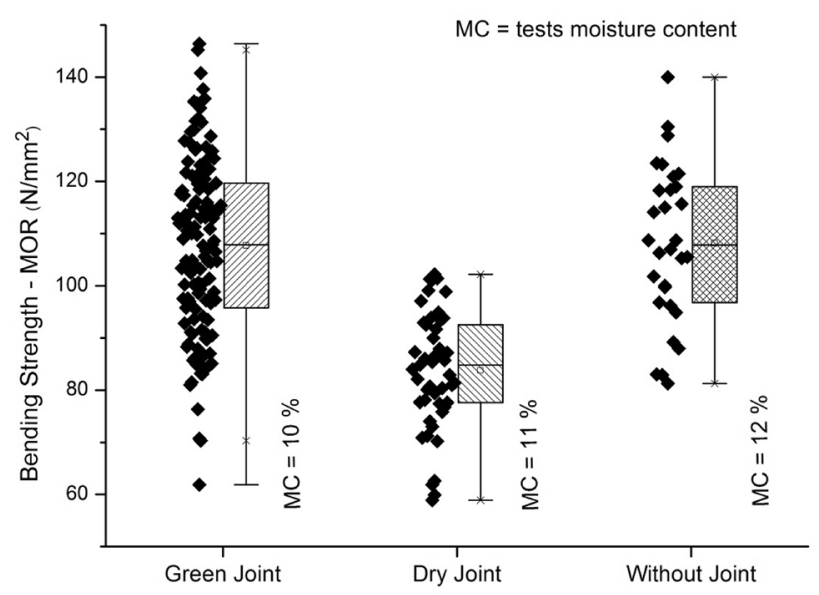

Fig. 7 Comparison of mean bending strength values

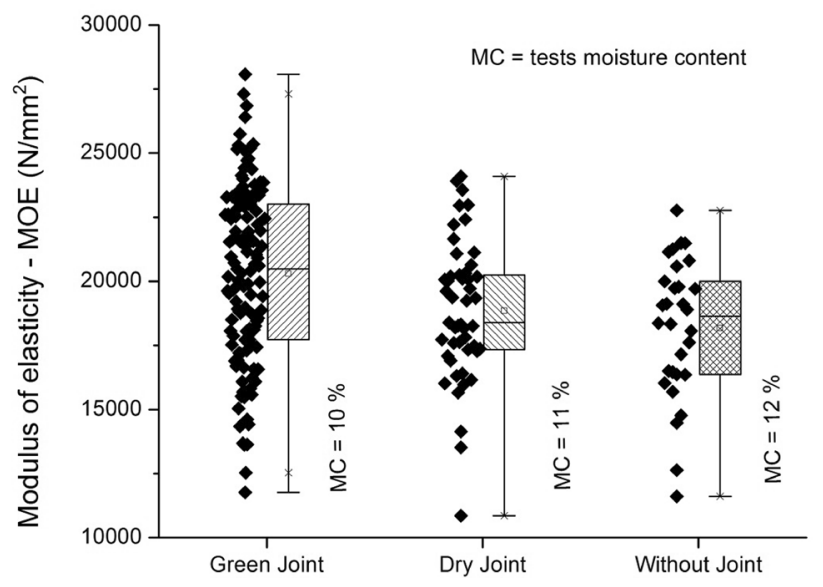

Fig. 8 Comparison of mean modulus of elasticity values

this sense, they are also included in the results and in the discussion.

According to the results obtained for green and dry finger joints, and considering only the characteristic values determined as the 5th percentile, a D50 class (strength class included in the EN 338 (2016) norm with the following characteristic values: $\mathrm{MOR}=50 \mathrm{~N} / \mathrm{mm}^{2} ; \mathrm{MOE}=14,000 \mathrm{~N} /$ $\mathrm{mm}^{2}$; density $=620 \mathrm{~kg} / \mathrm{m}^{3}$ ) was achieved, while solid wood without finger joints achieved a D45 class (strength class included in the EN 338 norm (2016) with the following characteristic values: $\mathrm{MOR}=45 \mathrm{~N} / \mathrm{mm}^{2} ; \mathrm{MOE}=13,500 \mathrm{~N} / \mathrm{mm}^{2}$; density $=580 \mathrm{~kg} / \mathrm{m}^{3}$ ).

Due to the characteristics of the solid timber of E. globulus, under the visual classification "MEF" in dry state, according to the criteria of the Spanish standard UNE 56546 (2013), this species is classified in the EN 1912 (2012) standard, with D40 and D45 strength class. This shows that the characteristic results obtained with green finger joints 
Table 5 Results of characteristic values (5th percentile) of MOR (bending strength), MOE (global elasticity modulus) and density

\begin{tabular}{llll}
\hline $\begin{array}{l}\text { Finger joint } \\
\text { group }\end{array}$ & MOR $\left(\mathrm{N} / \mathrm{mm}^{2}\right)$ & MOE $\left(\mathrm{N} / \mathrm{mm}^{2}\right)$ & Density $\left(\mathrm{Kg} / \mathrm{m}^{3}\right)$ \\
\hline Green & 83.1 & 14,476 & $646^{*}$ \\
Dry & 62.2 & 14,746 & $662^{*}$ \\
Without finger & 82.9 & 13,567 & 710 \\
\hline
\end{tabular}

*Determined as a mean of the density of each part joined at $12 \% \mathrm{MC}$

would initially meet the criteria of the currently most strict E. globulus grade.

In relation to the results of other authors with other species of hardwood, such as Crafford and Wessels (2016) and Wessels et al. (2020) with E. grandis, using the green finger joint is feasible and has a good structural classification, similar to that of solid wood without finger joints. It allows using E. globulus green gluing with wood to produce engineered products with high added value.

\subsection{Comparison between MOR and MOE with individual, mean and characteristic values}

A simple graphic comparison was performed between the individual, mean and characteristic values of MOE and MOR. It can be restated that there was no significant variation between the green finger joints and the wood without finger joints in the characteristic values of MOR and MOE (large square symbols for green finger joints and circles for non-finger joint wood in Fig. 9).

However, a higher characteristic MOR value was found in the green finger joints with respect to dry finger joints, while their characteristic MOE was very similar (large symbols of circles and triangles in Fig. 9). The individual values of green finger joints show a regression fit (long dashed line in Fig. 9) that lies between the regression of the individual values of lamellas of dry finger joints and those of solid wood lamellas without finger joints.

\section{Conclusion}

Density and bending strength tests of finger-jointed wet wood show that there is no significant difference with solid wood. The mean value of density and MOR had no statistically significant difference between green finger joints and wood without finger joints and these values are very close. On the contrary, significant differences and higher mean MOE value were obtained with finger-jointed green wood with respect to dry finger-jointed wood and solid wood. The 5 th percentile values of strength (MOR and MOE) obtained from the results of green glued finger joints and solid wood without finger joints were very similar, despite the slight reduction in characteristic density values of the green finger joints.

Therefore, the green finger joint shows better results than the dry finger joint, and such results are very close to solid wood without finger joints, which clearly indicates that gluing finger joints in green wood is feasible and improves the quality of the joints with eucalyptus wood. The characteristic results obtained with green finger joints would initially meet the criteria of the current most strict solid E. globulus grade. These results, along with other results obtained by previous works with green hardwood finger joints, confirm the potential of using green wood to develop engineered products, which would allow using waste material from sawmills and other lower quality wood byproducts to give them added value. However, although a green finger joint could be used for structural timber products, further research on criteria of green wood grade in a previous classification is still required. Considering that knotless pieces were used, the characteristic values of the mechanical properties analysed would include the elements studied in D45 class.

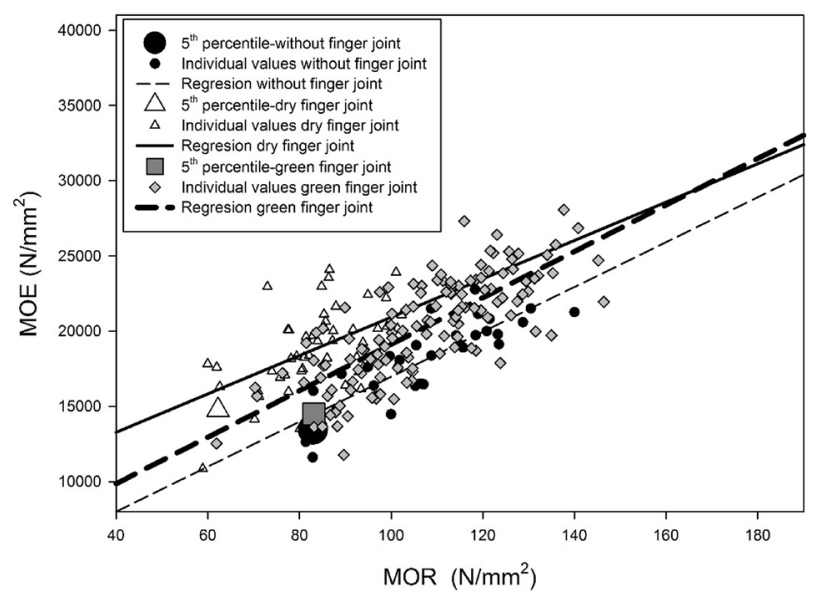

Fig. 9 Comparison of the individual and characteristic values of MOE and MOR 
Acknowledgements The authors would like to thank the collaboration of Dr. Maximilian Wentzel in the elaboration of this document, and the tutors of the $\mathrm{PhD}$ of the first author, ret.-professor Dr. Carlos Baso López and Dr. Francisco López-Suevos. On behalf of all authors, the corresponding author states that there is no conflict of interest.

Funding Open Access funding provided thanks to the CRUE-CSIC agreement with Springer Nature.

Open Access This article is licensed under a Creative Commons Attribution 4.0 International License, which permits use, sharing, adaptation, distribution and reproduction in any medium or format, as long as you give appropriate credit to the original author(s) and the source, provide a link to the Creative Commons licence, and indicate if changes were made. The images or other third party material in this article are included in the article's Creative Commons licence, unless indicated otherwise in a credit line to the material. If material is not included in the article's Creative Commons licence and your intended use is not permitted by statutory regulation or exceeds the permitted use, you will need to obtain permission directly from the copyright holder. To view a copy of this licence, visit http://creativecommons.org/licenses/by/4.0/.

\section{References}

Baso C, Casas JM, Furones P, Bouzón A (2004) Steam treatment to improve the quality and increase the rate of drying of Eucalyptus globulus Labill. proposal and execution of a test on quarter-sawn boards. In: Paper presented at the 4th COST E15 Workshop. Methods for Improving Drying Quality of Wood, Compostela, Spain, May 30-31

Blümer H (2005) Integrating green finger jointing into the production process. In: Paper presented at the International Conference/Workshop Green Gluing of Wood: process-Products-Market, COST Action E34 Bonding of Wood in cooperation with SP Swedish National Testing and Research Institute, Borås, Sweden, April 7-8

Crafford PL, Wessels CB (2016) The potential of young, green fingerjointed Eucalyptus grandis lumber for roof truss manufacturing. South Forests 78:61-71. https://doi.org/10.2989/20702620.2015. 1108618

Di Landro L, Pegoraro M, Bordogma L (1991) Interactions of polyether-polyurethanes with water vapour and water-methane separation selectivity. J Membrane Sci 64:229-236. https://doi.org/10. 1016/0376-7388(91)80093-L

DIN 68140-1 (1999) Wood finger-jointing-Part 1: finger jointing of softwood for load-bearing structures. German Institute for Standardization, Berlin

EN 14080 (2013) Timber structures - Glued laminated timber and glued solid timber-requirements. European Committee for Standardization, Brussels

EN 15497 (2014) Structural finger jointed solid timber-performance requirements and minimum production requirements. European Committee for Standardization, Brussels

EN 1912 (1912) (2012) Structural timber-strength classes—assignment of visual grades and species. European Committee for Standardization, Brussels

EN 338 (2016) Structural timber-strength classes. European Committee for Standardization, Brussels

EN 408 (2012) EN 408:2011+A1:2012 Timber structures - Structural timber and glued laminated timber-Determination of some physical and mechanical properties. European Committee for Standardization, Brussels

Fernández-Golfín JI, Díez R, Hermoso E, Baso C, Casas JM, GonzálezPrieto O (2007) Caracterización de la madera de E. globulus para uso estructural [Characterization of E. globulus wood for structural use]. Boletín Informativo CIDEU 4:91-100

Källander B, Welling J (2005) Drying of green glued material—Drying technology and quality control requirements. In: Paper presented at the International Conference/Workshop Green Gluing of WoodProcess-Products-Market, COST Action E34 Bonding of Wood in cooperation with SP Swedish National Testing and Research Institute, Borås, Sweden, April 7-8

Karastergiou S, Mantanis GI, Skoularakos K (2008) Green gluing of oak wood (Quercus conferta L.) with a one-component polyurethane adhesive. Wood Mater Sci Eng 3:79-82. https://doi.org/10.1080/ 17480270802605537

Kirkpatrick JB (1975) Natural distribution of Eucalyptus globulus Labill. Aust Geogr 13(1):22-35. https://doi.org/10.1080/000491875087026 75

Mantanis G, Karastergiou S, Barboutis I (2011) Finger jointing of green Black pine wood (Pinus nigra L.). Eur J Wood Prod 69:155-157. https://doi.org/10.1007/s00107-010-0435-9

$\mathrm{Na}$ B, Pizzi A, Delmotte L, Lu X (2005) One-component polyurethane adhesives for green wood gluing: Structure and temperature-dependent creep. J Appl Polym Sci 96:1231-1243. https://doi.org/10.1002/app.21529

Parker JR (1994) Greenweld process for engineered wood products. In: Paper presented at the International Panel and Engineered Wood Technology Exposition, Atlanta, Georgia, United States of America, October 5.

Pommier R, Elbez G (2006) Finger-jointing green softwood: evaluation of the interaction between polyurethane adhesive and wood. Wood Mater Sci Eng 1:127-213. https://doi.org/10.1080/1748027070 1217269

Srivaro S, Börcsök Z, Pásztory Z, Jantawee S (2019) Finger Joint Performance of Green-Glued Rubberwood (Hevea brasiliensis) Lumber. BioRes 14:9110-9116

Stephens PL (1995) Improved recovery through green finger joining - the greenweld process. In: Paper presented at the Western Dry Kiln Association Meeting, Reno, Nevada, United States of America, May $10-12$

Sterley M, Blümer H, Wålinder MEP (2004) Edge and face gluing of green timber using a one-component polyurethane adhesive. Holz Roh Werkst 62:479-482. https://doi.org/10.1007/ s00107-004-0517-7

Sterley M, Serrano E, Enquist B, Hornatowska J (2014) Finger jointing of freshly sawn norway spruce side boards-a comparative study of fracture properties of joints glued with phenol-resorcinol and onecomponent polyurethane adhesive. In: Aicher S, Reinhardt HW, Garrecht $\mathrm{H}$ (eds) Materials and joints in timber structures RILEM, vol 9. Springer, Dordrecht, pp 325-339. https://doi.org/10.1007/ 978-94-007-7811-5 30

Troughton GE, Chow S (1979) Fingerpointing unseasoned, rough western red cedar lumber using the WFPL [Western Forest Products Laboratory] method. Technical Report Western Forest Products Laboratory Forintek Canada Corp (Canada).

Troughton GE, Chow S (1980) Finger-jointing kiln-dried and unseasoned white spruce lumber using the "WFPL" [Western Forest Products Laboratory] method. For Prod J 30:48-49

UNE 56546 (2013) Visual grading for structural sawn timber. Hardwood timber. Spanish Standardization, Madrid.

Wessels CB, Nocetti M, Brunetti M, Crafford PL, Pröller M, Dugmore MK, Pagel C, Lenner R, Naghizadeh Z (2020) Greenglued engineered products from fast growing Eucalyptus trees: a review. Eur J Wood Prod 78:933-940. https://doi.org/10.1007/ s00107-020-01553-6

Xunta de Galicia (2018) 1a Revisión del Plan Forestal de Galicia [1st Review of the forestry plan of Galicia]. Santiago de Compostela, Spain

Publisher's Note Springer Nature remains neutral with regard to jurisdictional claims in published maps and institutional affiliations. 